some of the stigma which attaches to them. Produced as part of the Royal College of Psychiatrists' anti-stigma campaign 'Changing Minds', whose Chairman is the editor, it offers useful and often moving insights into the causes, experiences and misunderstanding of, and reactions to, what lies behind generic diagnoses such as personality disorder, schizophrenia, depression, dementia, eating disorders, and alcohol and drug misuse and the stigma that stems from the labels.

The joy and the novelty of this book is that it is freely available on the internet. Its scope is almost too large for a single book, so that the ability to search for the nuggets one wants rather than to start at the beginning and read to the end, is invaluable. Perhaps more importantly, although most of the articles will attract specialists in mental illness or those with experience of it, computerisation may tempt some of those less knowledgeable, who browse the internet as a pastime, to stray into the world of mental illness without the provocation of the sensationalist press, thus opening more minds to the realities rather than the myths of mental disorder.

A brief scan of the contents list highlights the way in which the diverse mass of material has been helpfully clustered together. Each chapter has a theme which relates to all or most of the illnesses in question, underlining the commonality of stigmatising or other assumptions about all types of mental illness. The history of stigmatisation, its origins and strategies to deal with it are three examples of this grouping. Separate chapters cover the law and mental illness, creativity and mental disorder, and spirituality and mental illness. For me as a non-specialist reader, the chapter which had the most impact was Chapter 2, in which courageous individuals give mind-opening personal descriptions of what it is like to live with various mental disorders, and those who love and care for them, as well as experts, describe the effect of stigma on their everyday lives. This chapter above all brings home the title of the book: Every Family in the Land. Yesterday, today or tomorrow, this might be your family. This book is available without cost as an invaluable resource to which you can turn at will.

Margaret Clayton Former Chairman, Mental Health Act Commission, Maid Marian House, 56 Hounds Gate, Nottingham NGI 6BG, UK
Pathologies of the West. An Anthropology of Mental IIIness in Europe and America

By Roland Littlewood. London: Continuum. 2002. 286 pp. $€ 65.00$ (hb), $€ 25$ (pb).

ISBN 0826458157 (hb), 0826458165 (pb)

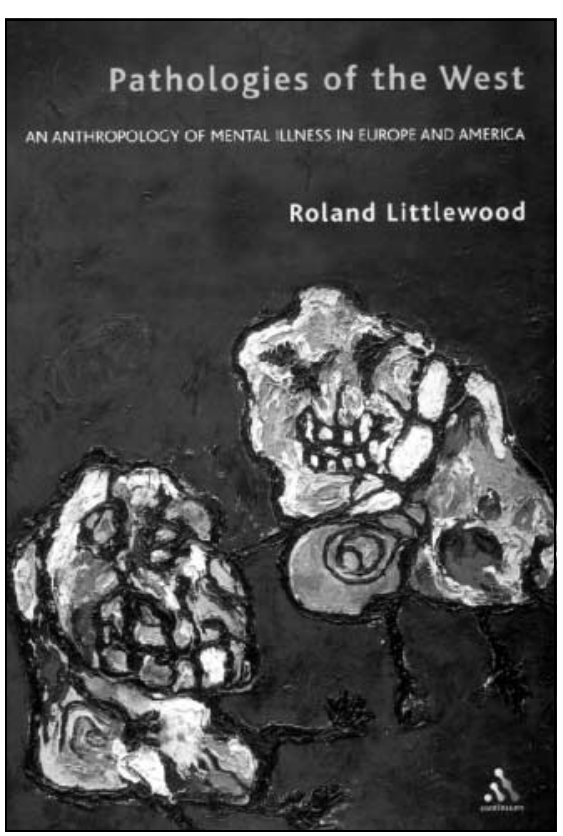

Psychiatry could learn a great deal from social anthropology. Most English-speaking psychiatrists are trained and think largely in the languages of biology and pharmacology, and so do not find it easy to appreciate the complex influences of their patients' cultural backgrounds, assumptions and beliefs on the shifting ways in which they express their distress and their fears. As a result, we are often nonplussed by contemporary phenomena like myalgic encephalomyelitis and the Gulf War and total allergy syndromes. So there is plenty of scope for an anthropology text aimed at psychiatrists.

Sadly, this is not it. It is probably not written for psychiatrists, or even for doctors, and although Littlewood writes fluently it is heavy going. He writes sensibly enough about the cultural influences on the phenomena and the rising female incidence of parasuicide, agoraphobia, anorexia and obesity, but most of his comments are hardly original. Moreover, the bulk of the book is devoted to incest, military rape, domestic sieges and the links between late 19th-century French hysteria and late 20thcentury American multiple personality disorder. His observations here are more interesting and, I would guess, more shrewd, but none of these phenomena is a key issue for busy National Health Service psychiatrists. If you are well-heeled and will not be put out by frequent references to instrumentality, mimesis and subdominance - and if you are familiar with symbolic inversions, transgressive arguments, reversal theory and contingent proximity - you might be fascinated to read this heavily referenced tome. But you will also be a fairly rare bird.

R. E. Kendell Honorary Professor of Psychiatry, University of Edinburgh, 3 West Castle Road, Edinburgh EHIO 5AT, UK

\section{Defining Psychopathology in the 2Ist Century. DSM-IV and Beyond}

Edited by John E. Helzer \& James J. Hudziak. Washington, DC: American Psychiatric Publishing. 2002.272 pp. $€ 49.00$ (pb). ISBN I 585620637

The inspirational title of this book suggests that it was conceived in the after-glow of the millennium celebrations. Indeed, the editors have drawn on lectures given at the year 2000 American Psychopathological Association meeting of the same title. The book is dedicated to the life and work of Samuel B. Guze, who was presented with the Joseph Zubin award at the meeting: that was the last occasion on which many of his friends and colleagues saw him before his death.

One of the difficulties facing editors of conference proceedings is that they generally have less direct control over chapter topics and content than editors of other multi-author books such as textbooks. This often means that the final product resembles the 'curate's egg': it is good in parts. Fortunately, John Helzer \& James Hudziak have avoided such problems and this egg is good throughout. They have produced a fine text that is both scholarly in content and exciting to read.

The contributions have been collected into four parts, the first entitled 'Definitional tensions'. A masterly opening chapter by Robert Kendell sets the current scene. This is followed by an intriguing dialogue between Professors Regier, Narrow, Wakefield \& Spitzer about the methodological and definitional issues raised by large-scale epidemiological studies in the USA. The second part, 'Defining psychopathology', explores how functional imaging could be 